\title{
Effect of Plasma Donation on Responses to Exhaustive Severe Intensity Cycle Ergometer Exercise
}

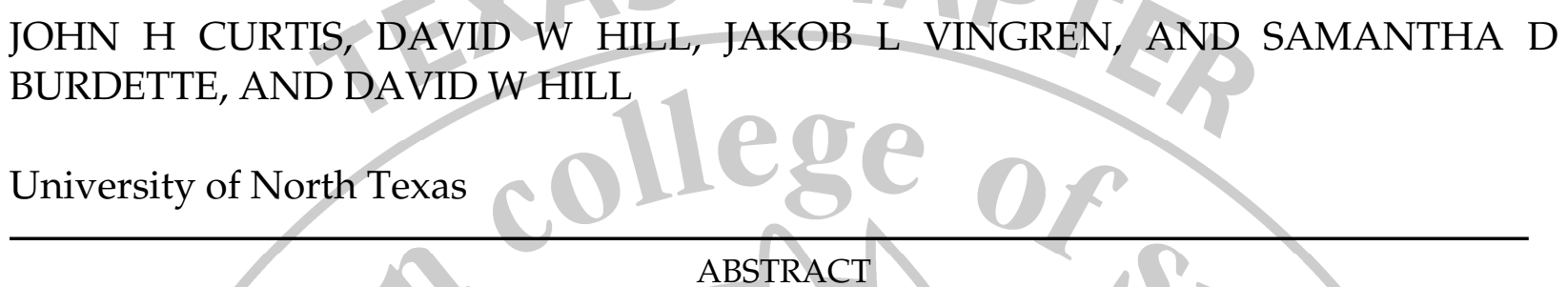

PURPOSE: The purpose of this study was to investigate the time course of the effects of plasma donation on responses to severe intensity exercise. METHODS: Four women (mean \pm SD: age, $27 \pm 7$ years; height, $163 \pm 13 \mathrm{~cm}$; weight, $62.9 \pm 12.0 \mathrm{~kg}$ ) and six men (age, $25 \pm 2$ years; height, $180 \pm 6 \mathrm{~cm}$; weight, 87.3 $\pm 6.2 \mathrm{~kg}$ ) perform exhaustive cycle ergometer tests under control conditions, and then $2 \mathrm{~h}, 2$ days, and 7 days following plasma donation. RESULTS: Times to exhaustion at baseline and $2 \mathrm{~h}, 2$ days, and 7 days following plasmapheresis were $262 \pm 41,229 \pm 59,259 \pm 67$, and $267 \pm 60 \mathrm{~s}$, respectively; performance time was reduced $(p=.052) 2 \mathrm{~h}$ after donation. Hemoglobin concentrations ([Hb]) before each test were $139 \pm$ $19,161 \pm 13,147 \pm 15$, and $144 \pm 10 \mathrm{~g} \cdot \mathrm{L}^{-1} ;[\mathrm{Hb}]$ was increased $2 \mathrm{~h}$ after donation. Maximal oxygen consumption $\left(\mathrm{VO}_{2} \max\right.$ ) values were $38 \pm 5,37 \pm 4,38 \pm 4$, and $38 \pm 5 \mathrm{~mL} \cdot \mathrm{kg}^{-1} \cdot \mathrm{min}^{-1} ; \mathrm{VO}_{2}$ max was not affected by donation. The time constants of the primary phase of the 2-component $\mathrm{VO}_{2}$ max response in the exhaustive severe intensity exercise were $27 \pm 6,29 \pm 8,29 \pm 8$, and $26 \pm 7$ s; the kinetics of the $\mathrm{VO}_{2}$ response were unaffected by plasma donation. CONCLUSION: The effects of plasma donation are short lived; no effects persists for two days. This information may be of value to athletes and others who might balance the altruism of plasma donation with personal concerns about performance.

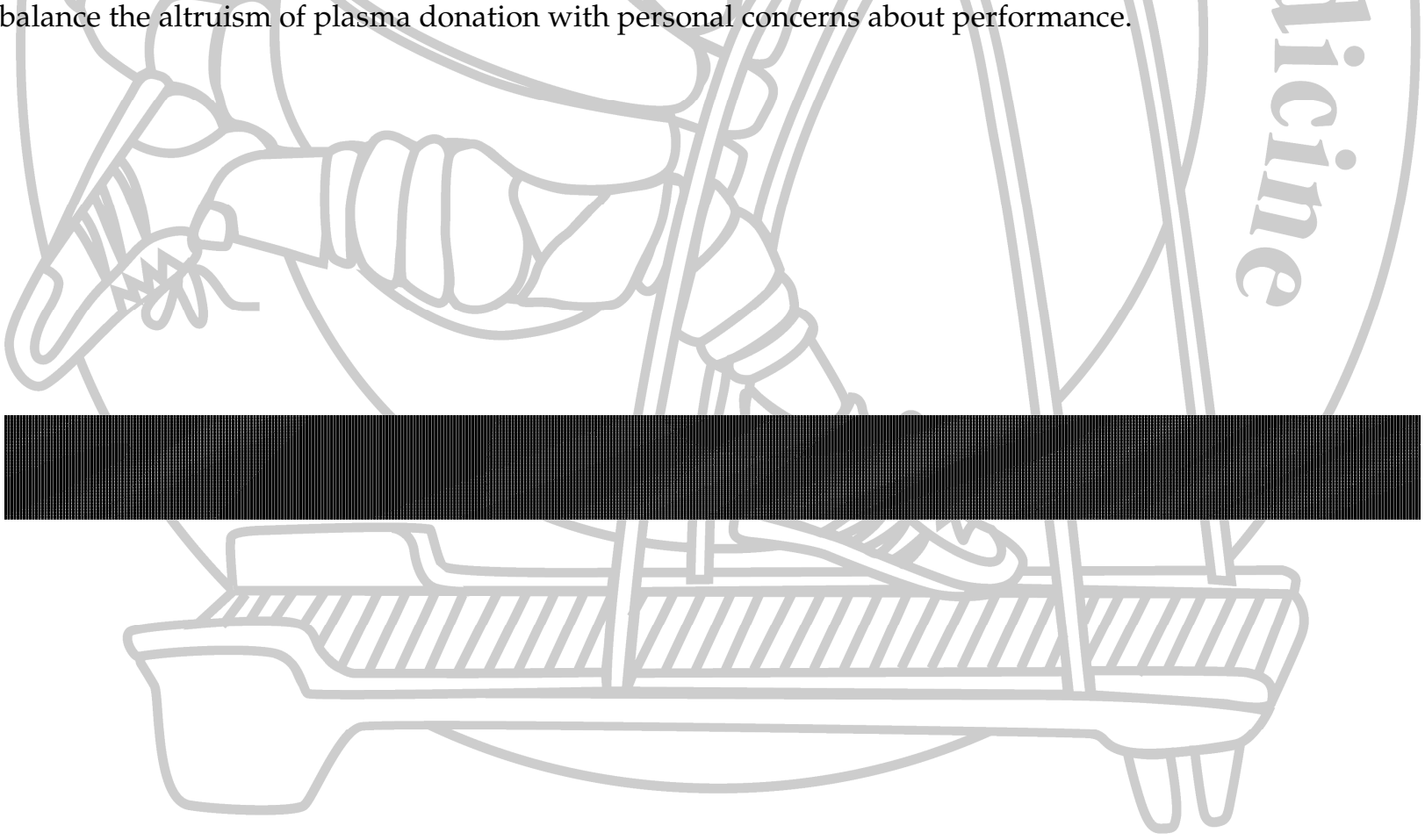

